\title{
Temporary Bonding Using Paper Inserted PPC Layer
}

\author{
Zhiyuan Zhu ${ }^{1}$, Kequan Xia ${ }^{1}$, Zhiwei X ${ }^{1}$, Hongze Zhang ${ }^{3}$, Haijun Lou ${ }^{2}$ \\ ${ }^{1}$ Ocean College, Zhejiang University, Zhejiang, China \\ ${ }^{2}$ Institute of Advanced Technology, Zhejiang University, Zhejiang, China \\ ${ }^{3}$ Nanjing Electronic Devices Institute, Nanjing, China
}

\begin{abstract}
Temporary bonding using paper inserted polypropylene carbonate (PPC) layer is demonstrated. The inserted paper layer can absorb photo acid generator (PAG)-induced acid and protect the substrate. Large improvements of bonding strength are achieved using paper inserted PPC layer. Especially, the bonding strength is much higher than that of PPC/PAG-PPC bonding for tissue paper. The results show that the paper fibers can absorb decomposed PPC and PAG-induced acid, thus protecting the substrate.
\end{abstract}

Keywords: temporary bonding; debonding; polypropylene carbonate

\section{Začasno bondiranje z uporabo s papirjem vnesene PPC plasti}

Izvleček: Prikazano je začasno bondiranje z vnosom plasti polipropilen karbonata (PPC) s pomočjo papirja. Vložena papirna plast lahko absorbira kislino generatorja fotokisline (PAG), s čimer zaščiti substrat. Uporaba PPC plasti omogoča velike izboljšave vezne trdnosti bonda. Zlasti je vezna trdnost precej višja kot pri uporabi PPC/PAG-PPC tkanine. Rezultati kažejo, da lahko papirna vlakna absorbirajo razgrajeno kislino, ki jo povzroča PPC in PAG, s čimer se zaščiti substrat.

Ključne besede: začasno bondiranje; debondiranje; polipropilen karbonat

*Corresponding Author's e-mail:xuzw@zju.edu.cn,

\section{Introduction}

Silicon wafer is the fundamentals of semiconductor industry [1-3]. Particular, the application of thin silicon wafers is an enabling technology for modern electronics as reduced wafer thickness integration enables shorter processing times and less cost [4-6]. All of this is advantageous for a low package height for chip cards, the requirement for higher power, and the search for System-in-a-Package (SiP) using chip stack methods.

Temporary bonding and debonding are essential for fabricating thin wafers $[7,8]$. On the one hand, the bonding strength should be high in order to endure the mechanical polishing/thinning. On the other hand, debonding process is required to be simple, low cost and of high reliability. To achieve the above requirements, we propose photo acid generator (PAG) loaded polypropylene carbonate (PPC) debonding at room temperature without any solvent based or ultraviolet
(UV) treatment [9]. Subsequently, PPC/PAG-PPC bonding structure is proposed [10]. The inserted PPC layer serve as the passivation layer, which can absorb the PAG-induced acid. The bonding layer loses adhesion to the substrate and automatic debonding is achieved when center region of the PPC layer is decomposed. The PAG-induced acid is separated from the bonding substrate, which improve the bonding strength and protect the substrate. Application of PPC as temporary adhesive for fabrication of sensor chip has also been demonstrated [11].

The main aim of this work is to develop a method to further increase the PPC temporary bonding strength. Herein, we propose temporary bonding using paper inserted PPC layer. Further improvement of bonding strength is achieved. 


\section{Experimental}

Temporary bonding and debonding using paper inserted PPC layer is proposed to protect the substrate and improve the bonding strength. The bonding structure is shown in Fig. 1a. The PPC polymers (QPAC 40) used in this work were obtained from Empower Materials and have a molecular weight of $196 \mathrm{~kg} / \mathrm{mol}$. The PPC solution was prepared by dissolving pure PPC in acetone under constant stirring to form a $20 \mathrm{wt} \%$ solution. Tetrakis(penta-fluorophenyl) borate-4-methylphenyl [4-(1-methylethyl)-phenyl] iodonium tetrakis (pentafluorophenyl) borate is used as the PAG and obtained from tokyo chemical industry Co. The PAG-PPC solution was prepared by adding PAG (about $1 \mathrm{wt} \%$ of the PPC) to the PPC solution. Printer paper, tissue paper and silicone paper are used as the paper insertion layer. The main chemical compositions of the paper insertion are cellulose, hemicellulose, lignin, calcium carbonate, etc. The paper fiber can interlace with PPC polymer and absorb PAG-induced acid. Silicon paper is fabricated by treating printer paper with silicone, so it is nonstick and heatproof. The glass substrates $(10 \mathrm{~mm} \times 10 \mathrm{~mm})$ are obtained from Dongsheng Corporation with density of $2.2 \mathrm{~g} / \mathrm{cm}^{3}$, tensile strength of $\sim 50 \mathrm{MPa}$ and inflection resistance of 60-70 MPa. The PPC solution was poured onto the glass substrate facade. The acetone was then removed by baking the specimen for $10 \mathrm{~min}$ at $60^{\circ} \mathrm{C}$. Subsequently, paper layer is attached on PPC surface, followed by dropping of PAG-PPC solution and solvent evaporation. Bonding of the fabricated samples is achieved using a hot press (Carver, Inc.) at bonding pressure of $0.2 \mathrm{MPa}$. The bonding temperatures for thermal bonding 1 and 2 are $100^{\circ} \mathrm{C}$ and $200^{\circ} \mathrm{C}$, respectively. The morphology of the substrate surface is examined using Hitachi TM3000 scanning electron microscope (SEM).

\section{Results and Discussions}

The decomposition products of PPC include cyclic propylene carbonate (CPC), propylene glycol, and $\mathrm{CO}_{2}$, which indicates that decomposed PPC is liquid at room temperature. The (SEM image of typical paper fiber is shown in Fig. 2. It is obvious that the cellulose fiber of paper can absorb decomposed PPC and PAGinduced acid. Thus, PPC is less consumed and there is PPC remained beneath the paper layer, the substrate is protected and the bonding strength is improved. Under high bonding temperature $\left(>170^{\circ} \mathrm{C}\right.$, represent as thermal bonding 2 in Fig. 1a1), sufficient PAG-induced acid is produced, consuming the entire PPC layer between paper layer and achieving automatic debonding at room temperature without any solvent based or UV treatment. Under low bonding temperature $\left(<130^{\circ} \mathrm{C}\right.$, represent as thermal bonding 1 in Fig. 1a2), a portion of PAG is activated and less PAG-induced acid is produced, and a considerable portion of acid is also absorbed by paper fiber. Thus, a subsequent UV irradiation or heating is required to achieve complete debonding.

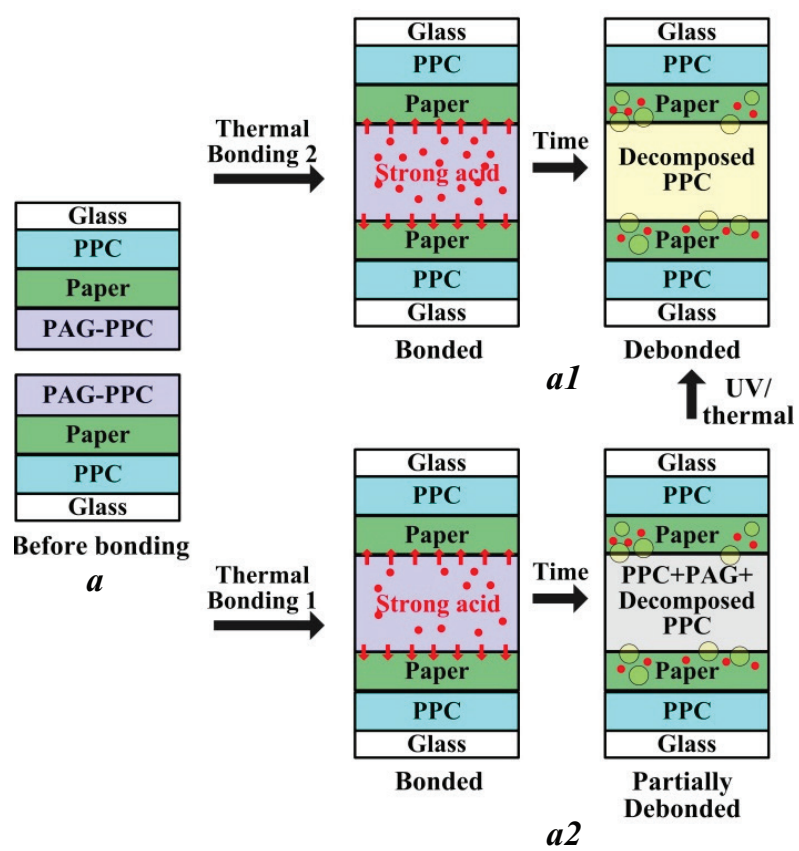

Figure 1: Schematic of temporary bonding and debonding process

a PPC/Paper/PAG-PPC bonding structure

a1 Bonding at high temperature $\left(>170^{\circ} \mathrm{C}\right)$ and subsequent automatic debonding for PPC/Paper/PAG-PPC structure

a2 Bonding at low temperature $\left(<130^{\circ} \mathrm{C}\right)$ and subsequent debonding for PPC/Paper/PAG-PPC structure

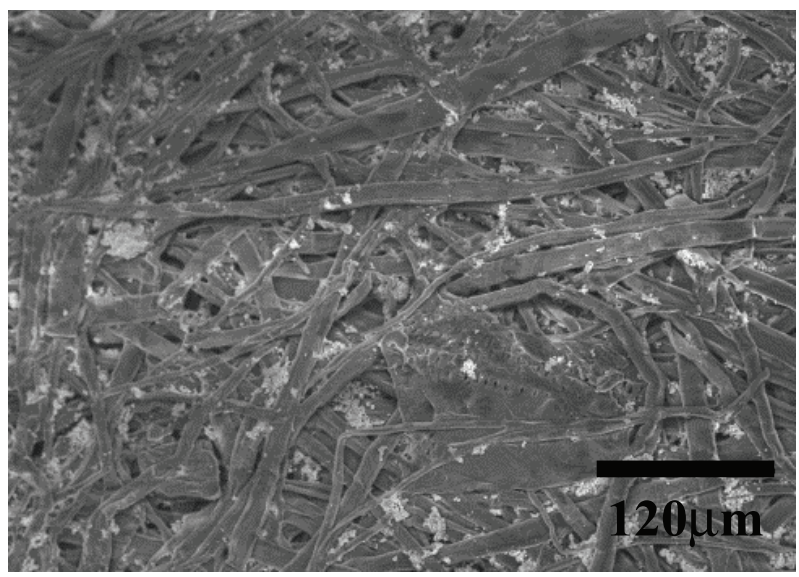

Figure 2: SEM image of typical paper fiber

Glass substrates are used to demonstrate and compare the bonding results. The results are shown in table 1. It 
can be seen from table 1 that large improvements of bonding strength are achieved using paper inserted PPC layer. This effect is especially obvious for tissue paper, which absorb more PAG-induced acid. For printer paper and tissue paper, the bonding strength decrease significantly when bonding temperature increases to $200^{\circ} \mathrm{C}$, which is probably caused by damage of fiber structure. On the contrary, there is no significant decrease of bonding strength of silicone paper inserted PPC layer, which can be attributed to the heat resistance property of silicone paper.

In order to adjust the debonding time, heating or UV irradiation processes after bonding is used. All the bonded samples fabricated in this work are successfully debonded.

Table 1: Comparison of the bonding strength of different methods demonstrated using glass substrates perature, excessive PAG-induced acid is produced, consuming the PPC protection layer at multiple locations and and leaving PPC residue. The PAG-induced acid can cause damage to the substrate and decrease the reliability of circuit where PPC protection layer is consumed.

Fig. 4 shows the SEM image of typical surface morphology of debonded samples for PPC/silicone paper/PAGPPC under thermal bonding 2. The results show that the upper surface of paper is the debonding interface, which indicate that the PPC layer beneath paper insertion is hardly decomposed. This corresponds well with the bond mechanism which state that paper fibers can absorb decomposed PPC and PAG-induced acid. Thus, PPC is less consumed and there is PPC remained beneath the paper layer, the substrate is protected and the bonding strength is improved. The improvements of bonding strength have also been demonstrated in Table 1.

\begin{tabular}{|c|c|c|}
\multirow{2}{*}{ Ref. } & \multicolumn{2}{|c|}{ Bonding strength (MPa) } \\
\cline { 2 - 3 } & Thermal bonding 1 & Thermal bonding 2 \\
\hline Printer paper in this work & $3.9 \pm 0.45 \mathrm{MPa}$ & $1.7 \pm 0.33 \mathrm{MPa}$ \\
\hline Tissue paper in this work & $4.1 \pm 0.29 \mathrm{MPa}$ & $2.3 \pm 0.12 \mathrm{MPa}$ \\
\hline Silicone paper in this work & $3.5 \pm 0.19 \mathrm{MPa}$ & $3.2 \pm 0.43 \mathrm{MPa}$ \\
\hline PAG-PPC bonding in [9] & $3.0 \pm 0.34 \mathrm{MPa}$ & $2.1 \pm 0.18 \mathrm{MPa}$ \\
\hline PPC/PAG-PPC bonding in [10] & $3.3 \pm 0.26 \mathrm{MPa}$ & $2.7 \pm 0.25 \mathrm{MPa}$ \\
\hline
\end{tabular}

The surface morphologies of debonded samples were observed by SEM. Fig. 3 shows the SEM image of typical surface morphology of debonded samples for PAGPPC bonding under thermal bonding 2. PPC residue was observed. The results correspond well with the bond mechanism which state that under high bonding tem-

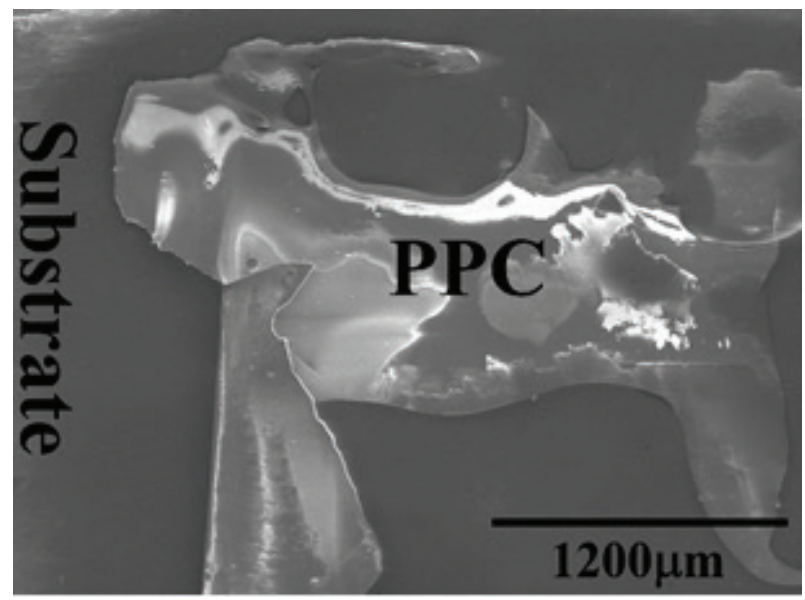

Figure 3: SEM image of typical surface morphology of debonded samples for PAG-PPC bonding under thermal bonding 2
Figure 4: SEM image of typical surface morphology of debonded samples for PPC/silicone paper/PAG-PPC under thermal bonding 2 .

\section{Conclusion}

This letter proposes temporary bonding and debonding using paper inserted PPC layer. The paper insertion can absorb PAG-induced acid and increase bonding strength. In order to adjust the debonding time, heating or UV irradiation processes after bonding is used.

\section{Acknowledgments}

This work was supported by National Natural Science Foundation of China (Grant No. 61804132). The author would like to thank the Animal Science Experimental Teaching Center of Zhejiang University for SEM characterization. The author would like to thank Prof. Yufeng Jin and Prof. Min Yu from Peking University for their help in previous work. The author would also like to 
thank the anonymous reviewer for the valuable judgment of this paper.

\section{References}

1. B. Tunaboylu, Space transformer connector characterisation for a wafer test system, Informacije MIDEM, 47[4] (2017) 255-260.

2. B. Tunaboylu, Performance of Ni-alloy MEMSprobes coated with PdCo films in semiconductor wafer test, Informacije MIDEM, 46[2] (2016) 80-90.

3. X. S. Zhang, Fabrication and characterization of squama-shape micro/nano multi-scale silicon material, Science China Technological Sciences, 55[12] (2012) 3395-3400. https://doi.org/10.1007/ s11431-012-4853-2

4. S. L. Ma, et al., Fabrication and characterization of a tungsten icroneedle array based on deep reactive ion etching technology, Journal of Vacuum Science \& Technology B, Nanotechnology and Microelectronics: Materials, Processing, Measurement, and Phenomena, 34[5] (2016) 052002. https://doi.org/10.1116/1.4960715

5. R. N. Fang, et al., Characteristics of coupling capacitance between signal-ground TSVs considering MOS effect in silicon interposers, IEEE Transactions on Electron Devices, 62[12] (2015) 4161-4168. https://doi.org/10.1109/ ted.2015.2494538

6. X. Sun, et al., Measurement-based electrical characterization of through silicon vias and transmission lines for 3D integration, Microelectronic Engineering, 149[5] (2016) 145152. https://doi.org/10.1016/j.mee.2015.10.010

7. Y. Guan, et al., Fine-pitch through-silicon via integration with self-aligned back-side benzocyclobutene passivation layer, IET Micro \& Nano Letters, 11[10] (2016) 619. https://doi. org/10.1049/mnl.2016.0267

8. P.Garrou, Handbook of 3D integration (WileyV(H), 2008.

9. Z. Zhu, et al., Temporary Bonding/Debonding of Silicon Substrates Based on Propylene Carbonate, Journal of Electronic Packaging, 137[4] (2015) 044501. https://doi.org/10.1115/1.4031750

10. Z. Zhu, et al., PPC-based bilayer temporary bonding and debonding, Microelectronic
Engineering, 180[5] (2017) 5-7. https://doi. org/10.1016/j.mee.2017.05.029

11. X.Xue, etal., Heat-Depolymerizable Polypropylene Carbonate as a Temporary Bonding Adhesive for Fabrication of Flexible Silicon Sensor Chips, IEEE Transactions on Components Packaging \& Manufacturing Technology, 7[11] (2017) 1751-1758. https://doi.org/10.1109/ TCPMT.2017.2742554

Arrived: 27. 05. 2018

Accepted: 24. 10. 2018 